Letter

\title{
The Influence of Heat Treatment in Orthodontic Arches Made of
}

\section{Stainless Steel Wire}

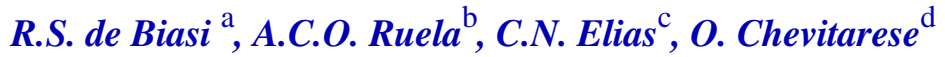 \\ ${ }^{a}$ Departamento de Engenharia Mecânica e de Materiais, Instituto Militar de \\ Engenharia, 22290-270 Rio de Janeiro - RJ, Brazil \\ ${ }^{\mathrm{b}}$ Faculdade de Odontologia, Universidade de Alfenas, 37130-000 Alfenas - MG, Brazil \\ ${ }^{\mathrm{c}}$ Departamento de Engenharia Metalúrgica, Universidade Federal Fluminense, \\ 27260-740 Volta Redonda - RJ, Brazil \\ ${ }^{\mathrm{d}}$ Faculdade de Odontologia, Universidade Federal do Rio de Janeiro, \\ 20001-970 Rio de Janeiro - RJ, Brazil
}

Received: November 9, 1999; Revised: April 15, 2000

\begin{abstract}
The austenitic stainless steel of orthodontic wires may undergo phase transformation induced by plastic deformation and heat treatment for stress relief. In order to study these changes, arches were made with $0.0215 \times 0.027$ " orthodontic wires and ferromagnetic resonance measurements were performed. The results showed that the best heat treatment for recovery of the austenitic phase seems to be at $450{ }^{\circ} \mathrm{C}$ for $3 \mathrm{~min}$.
\end{abstract}

Keywords: phase transitions, ferromagnetic resonance

\section{Introduction}

In 1929, stainless steel wires began to be used in orthodontics and became popular due to their good formability, compatibility, corrosion resistance, toughness, resilience and low cost.

The stainless steel wires used in orthodontics belong to the AISI 304 type. In this series, stainless steels have $18-20 \% \mathrm{Cr}, 8-11 \% \mathrm{Ni}$ and the maximum amounts of $\mathrm{C}$, $\mathrm{Mn}$ and $\mathrm{Si}$ are $0.08 \%, 2 \%$ and $1 \%$, respectively ${ }^{1}$. The combination of $\mathrm{Cr}$ and $\mathrm{Ni}$ stabilizes the austenitic phase at body temperature. Chromium oxide seems to form a corrosion-resistant surface layer.

Austenitic stainless steels may be classified in two groups, depending on the stability of austenite under deformation: those which don't form martensite even after considerable plastic deformation and those which do. Most of series 300 stainless steels undergo martensitic transformation after cold work ${ }^{1,2}$. Steels with $8-11 \% \mathrm{Ni}$, such as AISI 304 steels, become harder after plastic deformation not only as a result of work hardening but also because of martensitic transformation induced by plastic deformation $^{2}$.

As a result of phase transformations induced by deformation, 304 stainless steels have a certain amount of $\alpha$ (bcc) and $\varepsilon$ (hcp) martensite which is a function of tempera-

ae-mail: imes4rsb@epq.ime.eb.br ture, alloy composition and plastic deformation ${ }^{2,3}$. Experimental results suggest that the martensite phase is responsible for the higher mechanical strength of these samples relative to undeformed samples ${ }^{4}$.

Thus, with deformation, part of the austenite is transformed to martensite, creating stress and regions of varying hardness in the arch. In order to eliminate this inconvenience, annealing is done to homogenize the mechanical properties of the wire and relieve stress. According to Ingerslev, ${ }^{5}$ this treatment should be done between 350 and $375^{\circ} \mathrm{C}$ for $4 \mathrm{~min}$. According to Mongonon, ${ }^{3}$ any treatment between 225 and $425{ }^{\circ} \mathrm{C}$ is adequate. Funk ${ }^{6}$ recommends the use of a color index; the best treatment would be the one that imparts a straw color to the arches.

The purpose of this work is to study the changes that occur in orthodontic arches when they are annealed and relate them to the presence of the austenitic and martensitic phases.

\section{Experimental}

Rounded corner AISI $304(0.07 \%$ C, 1.4\% Mn, 0.7\% $\mathrm{Si}, 18.9 \% \mathrm{Cr}, 8.2 \% \mathrm{Ni}$ ) orthodontic wires of $0.0215 \mathrm{x}$ 0.027 " cross section (T.P. Orthodontics, Inc.) were cut into pieces $8.50 \mathrm{~cm}$ long. Arches were made from these pieces 
with a radius of $24 \mathrm{~mm}$, using an arch former (Rocky Mountain I-9).

Thermal treatments were performed at 350, 400, 450 and $500{ }^{\circ} \mathrm{C}$ for two different intervals ( 3 and $4 \mathrm{~min}$ ) in a salt bath (Duferrit salt AS 140). The salt bath provides a faster and more homogeneous heating of the samples than heat treatment in a furnace. The temperature of the bath was monitored with a chromel-alumel thermocouple.

After the annealing step, the samples were quenched in water at room temperature and washed in running water. After that, a central section was cut from each arch for the ferromagnetic resonance (FMR) measurements.

FMR measurements were performed at room temperature using an X-band $(9.5 \mathrm{GHz})$ Varian E-12 spectrometer.

\section{Experimental Results and Discussion}

Figure 1 shows the FMR linewidth of the arch sections as a function of annealing time for several annealing temperatures. The linewidth of the wire as-received $(158 \mathrm{mT})$ is smaller than the linewidth of the wire after the heat treatments. This means that cold deformation induces a phase transformation from austenite to martensite. In the system $\mathrm{Fe}-\mathrm{Cr}-\mathrm{Ni}$ at low temperatures and with plastic deformation, two martensitic phases are observed: $\alpha$ ' (bcc, ferromagnetic) and $\varepsilon$ (hcp, paramagnetic) ${ }^{7}$. The fact that the linewidth has its lowest value after deformation suggests that an austenite-martensite transformation induced by stress has occurred. In the as-received wire, the martensite phase remains in the $\varepsilon$ form, which is paramagnetic.

When the samples are annealed, the linewidth first increases and then decreases. The increase is attributed to formation of the $\alpha$ martensite phase, which is ferromagnetic ${ }^{3}$. The subsequent decrease, which is not observed for all thermal treatments, is probably due to reversal to the austenite phase.

As can be seen in Fig. 1, the decrease in linewidth after an initial increase is not observed for samples treated at 350 and $400{ }^{\circ} \mathrm{C}$. This suggests that these temperatures are too low for a significant phase reversal to occur in the first 4 min of annealing.

In the case of samples annealed at 450 and $500{ }^{\circ} \mathrm{C}$, the linewidth starts to decrease after $3 \mathrm{~min}$ of treatment. The first treatment $\left(3 \mathrm{~min}\right.$ at $450{ }^{\circ} \mathrm{C}$ ) is considered to be the best heat treatment for orthodontic applications because, ac-

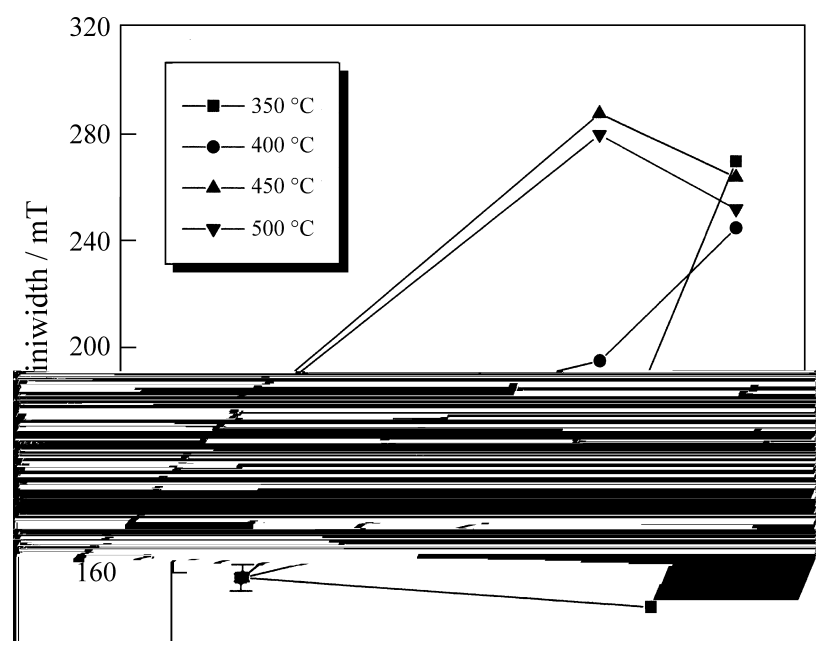

Figure 1. Ferromagnetic resonance linewidth of arch sections as a function of annealing time at four different annealing temperatures. The error bar applies to all data points.

cording to Elias, de Biasi and Chevitarese ${ }^{4}$, the maximum yield strength of the material corresponds to the maximum FMR linewidth.

\section{Conclusions}

The present results suggest that ferromagnetic resonance is a suitable technique for the study of phase transformations in orthodontic arches made of stainless steel wire. When applied to AISI 304 wires, the FMR technique showed that the best heat treatment for recovery of the austenitic phase is at $450{ }^{\circ} \mathrm{C}$ for $3 \mathrm{~min}$.

\section{References}

1. Associação Brasileira de Normas Técnicas NBR5601 - Aço Inoxidável - Classificação por Composição Química, Rio de Janeiro, 1981.

2. Philips, R.W. Skinner's Science of Dental Materials, W.B. Saunders, Orlando, USA, 1982.

3. Mongonon, P.L.; Thomas, G. Metal. Trans., v. 1, p. 1587, 1970.

4. Elias, C.N.; de Biasi, R.S.; Chevitarese, O. J. Mater. Sci. Lett., v. 12, p. 1703, 1993.

5. Ingerslev, C.H. Angle Orthod., v. 36, p. 236, 1966.

6. Funk, C.A. Angle Orthod., v. 21, p. 129, 1951.

7. Metals Handbook, ASM, Metals Park, OH, USA, v. 8, p. 424-426, 1973. 